\title{
Controlling Micro-CHP Generators as a Virtual Power Plant
}

\author{
C.A.G. $\underline{\text { MacRae }}^{\text {a }}$, R. Weiskircher ${ }^{\mathrm{b}}$, S. Dunstall ${ }^{\mathrm{b}}$, A.T. Ernst ${ }^{\mathrm{b}}$ and N. Kontoleon $^{\mathrm{b}}$

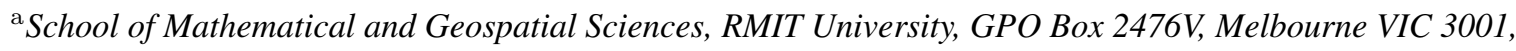 \\ Australia \\ ${ }^{\mathrm{b}}$ CSIRO Computational Informatics, Private Bag 33, Clayton South VIC 3169, Australia \\ Email: cameron.macrae@rmit.edu.au
}

\begin{abstract}
Deploying gas generators as a source of combined heat and power (CHP) in residential complexes offers the potential for substantial reductions in overall energy use and greenhouse-gas emissions. Here we use mathematical modelling to predict the operational behaviour of such generators in a hypothetical network of 100 residential apartment buildings.

In our models the generators produce electricity for local needs and for participation in the national energy market (NEM), while delivering space heating and hot water to the residences. The management strategies used optimise economic performance while satisfying the heat and power demands of the residential customers. The heat and power demand data has been synthesised using multiple information sources and is intended to represent a plausible demand pattern for residential apartment buildings in Victoria, Australia.
\end{abstract}

We present a linear programming based optimisation strategy for controlling micro-CHP generators that provide heating, hot water and electricity for apartment blocks. We assume that the operator of the generators can also participate in the NEM by providing a block of power once a day. Our system assumes that we have perfect prior knowledge about the power and heating demands in the apartment blocks as well as about the prices on the NEM.

By running the optimisation for each day of the year 2012, we show that an optimal strategy would provide about $67 \%$ of the annual electrical generation capacity of all generators for local use as well as for export to the NEM. We also show that the variable profit obtained from running the generators is extremely high on days with high NEM prices compared to days with average prices. Where it is unprofitable to operate the generators electricity is purchased from the grid at market rates.

An operator running CHP-generators according to the business model we describe in this paper must make sure that he or she can profit from the days with extreme NEM prices. A business model where the operator can only sell electricity to the occupants of the apartment blocks for the retail price has a much smaller earning potential. Therefore, allowing distributed generation operators with significant capacity to participate in the NEM should greatly encourage the installation of these devices and help reduce price peaks and congestion at the same time.

Our results also show that the savings in $\mathrm{CO}_{2}$ emissions from using CHP-generators in apartment buildings can be substantial with up to a $52 \%$ reduction in annual emissions compared to satisfying heat and electrical demand by conventional means. The $\mathrm{CO}_{2}$ savings are also strongly influenced by the wholesale prices in the NEM and being able to make use of high prices leads to significant additional savings which is demonstrated by the the amount saved on summer peak days.

In our future work, we want to examine control strategies that do not assume perfect knowledge about prices and demand on the next day but instead use available data like weather forecasts and the price forecasts provided by Australian Energy Market Operator (AEMO), combined with reacting to observed data. We could then use the system presented in this paper as a benchmark for measuring the predictive and adaptive strategies.

Acknowledgement: We acknowledge the valuable help and advice provided by Bill Lilley in the creation of this paper.

Keywords: Distributed generation, electricity markets, micro-chp 


\section{INTRODUCTION}

Thermal generators for electric power only transform part of the chemical energy contained in their fuel into electrical power, most of the difference is transformed into heat. Data from the Combined Heat and Power Partnership, US Environmental Protection Agency (2002) indicates that a typical steam turbine used in a large coal fired plant has an electrical efficiency of between $15 \%$ and $38 \%$ while a generator with combined heat and power (CHP) has a total efficiency (including heat) between $56 \%$ and $75 \%$. Therefore, using generators situated close to heat demand can reduce the emission of greenhouse gases compared to the currently dominant central generation model with large power plants far away from potential heat demand.

Control strategies for single CHP plants have already received considerable attention in the literature. Kong et al. (2005) present a linear program for controlling a CHP plant with afterburner and integrated absorption chiller for cooling loads. A very similar set-up is investigated by Cardona et al. (2006) for a plant at Malpensa airport in Italy. This paper also compares future investment options. Arcuri et al. (2007) use a mixed integer programming model (MILP) to optimally size a combined cooling, heat and power (CCHP) plant for a hospital complex. Cho et al. (2009) develop a network flow model to control CCHP operations and examine its performance under different climate conditions.

A number of papers simultaneously consider economic and environmental factors using multi-objective optimisation techniques (Carvalho et al., 2012; Fazlollahi et al., 2012; Kavvadias and Maroulis, 2010).

In this paper, we are concerned with decentralised micro-CHP generators. Alanne and Saari (2004) present a general review of issues that can influence decisions when considering small-scale CHP (like micro turbines or reciprocating engines) as an alternative energy source for buildings, with a focus on the European market.

Aki et al. (2005) present strategies for controlling a set of four homes with CHP fuel cells that can convert hydrogen to electric power and hot water. A distributed CHP and district heating system for Pordenone, Italy is considered by Casisi et al. (2009).

There are also a number of papers that propose algorithms for optimising the dispatch of decentralised CHP generators given a heat and power demand profile (Song et al., 1999; Rooijers and van Amerongen, 1994; Hernandez-Aramburo et al., 2005; Weber et al., 2006).

A comprehensive review of optimisation in energy generation is given by Bazmi and Zahedi (2011).

In contrast to these works, we do not assume a fixed demand that we are trying to match as cost-effectively as possible. We assume that a company runs a set of micro-CHP generators that provide hypothetical network of 100 apartment complexes with heat and hot water.

The company obtains a fixed fee for the heating services it provides and wants to earn additional profit from selling the aggregated electric power of the generators on the National Electricity Market (NEM) in Australia.

On this market, electricity producers submit bids one day ahead of dispatch. As described in the characterisation of the Australian energy market (AEMO Ltd, 2010), the market operator then determines for each time slot the market price and the power will be dispatched if the market price is higher than the price requested in the bid. Since the prices on the spot market can vary in orders of magnitude over one day, deciding when to sell how much electricity is critical for the profitability of the proposition.

The generated electric power that is not sold on the electricity market can be used to satisfy power demand in the apartment complexes for a fixed retail tariff.

\section{The Physical Model}

We assume a water based underfloor space heating system for the apartment complexes because it is well suited to CHP applications. These systems have a fairly large thermal inertia so that we can assume the energy demand for space heating to be almost constant over any given day.

The heating systems of the different apartment buildings are independent of each other. We assume that both the hot water service and the space heating service for each building use tanks containing hot water as energy storage. We also assume that there is a constant loss of energy per time slot from the tanks even if no hot water is used due to imperfect insulation. Hot water use by the residents of the apartment complex draws additional energy from the tanks.

For each of the two tank systems, there are two ways in which the temperature and thus the stored energy can be raised: Water can be heated in a heat exchanger using the hot exhaust of the generator or the water 
can be heated using gas boilers. We assume that the connection between added energy and water temperature is linear. The linearity assumption can be justified because the water temperature in the tanks is always kept inside a narrow range.

When a generator is running it produces a fixed amount of electrical power and a fixed amount of heat power. An arbitrary part of this heat power can be vented into the atmosphere. The remaining heat power passes through a heat exchanger and is split between the hot water and the space heating storage tanks associated with the generator. The ratio of the split can be freely chosen.

\section{The Optimisation Problem}

The control strategy determines when to operate the CHP-generators and how much electrical power to offer to the NEM in order to maximise the variable profit of the CHP-system.

We assume that we want to offer at most one block of power to the NEM each day. A block is a fixed power output provided during a time interval without interruptions. Therefore, the daily NEM bid is defined by three values:

1. The start time of the bid block

2. The duration of the bid block (defining the "width" of the block)

3. The electrical power we want to offer (defining the "height" of the block)

We define the variable profit of the CHP-system as the income generated by the NEM bid minus the fuel and maintenance costs of the CHP system plus the electricity and fuel costs for satisfying the same heat and local electricity demand by conventional means. It follows that the variable profit is:

$$
p_{v}=p_{n e m}+I c_{r}-c_{c h p}+c_{c}
$$

In this formula, $p_{n e m}$ is the income from the NEM bid, $I$ is the amount of electricity the CHP system provides for local use, $c_{r}$ is the retail cost of electricity, $c_{c h p}$ are the fuel and maintenance costs for the CHP solution and $c_{c}$ are the fuel costs for the boilers providing heat for the conventional solution. Note that $c_{c h p}$ is always greater or equal to $c_{c}$ since the CHP-solution has to provide the same heating services and the heat efficiency of a boiler is greater than the heat efficiency of generators.

The optimisation problem is quadratic because the revenue generated by the NEM bid in each time slot is obtained by multiplying the variable defining if the NEM bid spans the slot or not with the power level variable and the NEM price (a constant). All other components of the objective function as well as the constraints are linear.

We assume that the power demand in the NEM and thus the price is very low during the night for each day of the year. We also assume that the hot water demand in the apartment complexes is very low during the night and therefore that the heating systems connected to the generators are in a similar state early each morning before the hot water demand ramps up. Thus, we treat each day as a separate optimisation problem.

The matrix that defines the optimisation problem in not negative semi-definite so we cannot use convex optimisation techniques. Therefore, we split the problem into two parts:

\section{Determining the power level of the NEM bid}

2. Determining the time slots of the bid block and scheduling the generators

If we fix the power level of the NEM bid the optimisation problem becomes an integer linear program solvable with standard tools. Our solution method steps through a suitably chosen set of 10 power levels and computes an optimal solution for each power level. The power level where the highest profit was obtained together with the corresponding generator schedule and energy distribution is our solution for the given problem.

We compare results for two different generators, with the following technical data:

\begin{tabular}{l|c|c} 
& Capstone C65 & Cummins GGFE \\
\hline Type & Micro-turbine & Reciprocating engine \\
Electrical power & $65 \mathrm{~kW}$ & $30 \mathrm{~kW}$ \\
Heat power & $120 \mathrm{~kW}$ & $42.3 \mathrm{~kW}$ \\
Gas input & $230 \mathrm{~kW}$ & $103 \mathrm{~kW}$
\end{tabular}


To be able to use the two types of generators for the same buildings, we use either one Capstone C65 or two Cummins GGFE run as a single generator (total capacity 6.5 MW and 6.0 MW respectively).

We utilise the heat, power and energy demand simulator developed by Weiskircher et al. (2008).

\section{OPtimisation Results}

In this section, we first present the results for two single one day scenarios in detail to show the behaviour of the system and as an example of the data produced in the optimisation process. We then present results for the year of 2012 .

Figure 1 shows the NEM prices on the 9th of March 2012. We have chosen this day because the price in the NEM on this day does not have significant peaks but is also not particularly low, so it is similar to most days of the year.

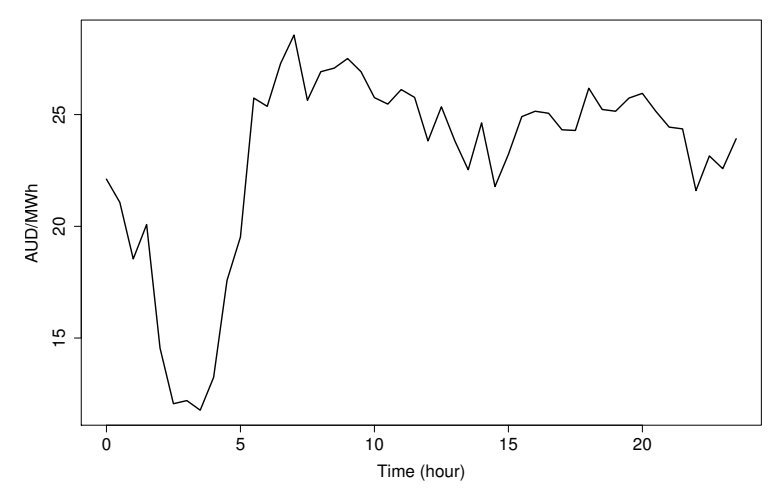

Figure 1. 9 March 2012

Power prices in the Victorian part of the NEM

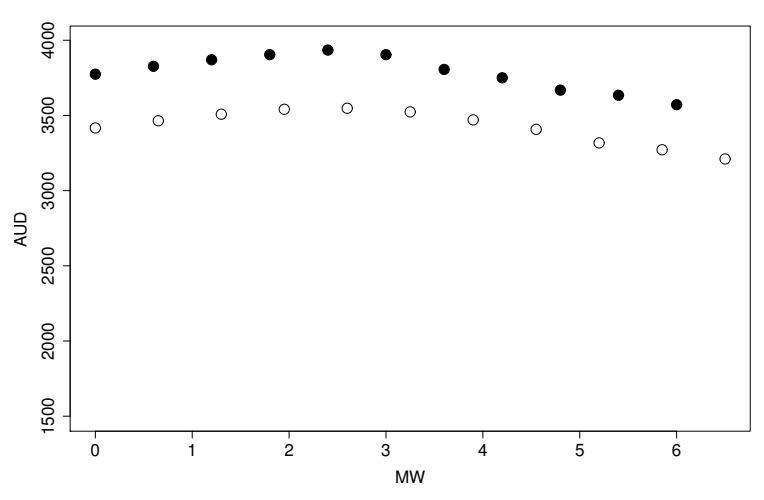

Figure 2. 9 March 2012

Profits against power level of NEM bid

Figure 2 shows the variable profits of the turbine operator depending on the power level of the NEM bid for the case where the Capstone turbines are used (empty circles) and where the Cummins engines are used (filled circles) versus the power level of the NEM bid.

For this particular day, where no extreme NEM prices occurred, the most profitable power levels for the bid (among the 10 we tried for each type of generator) was $2.4 \mathrm{MW}$ for the Cummins reciprocating engines and 2.6 MW for the Capstone turbines. Table 1 shows the characteristics of the best solutions found. The income from the NEM bids are quite small compared to the total variable costs and are less than 5\% of the total profit. Since the price in the NEM never reaches the retail price of electricity on this day, it is more profitable for the operator to concentrate on satisfying internal power demand and only sell small amounts of power to the wholesale market.

On the 29th of November 2012, the price in the Victorian part of the NEM reached a peak of 9325.98 AUD/MWh. This spike was caused by high temperatures resulting in increased use of air-conditioning equipment etc. Figure 3 shows the price development in the Victorian part of the NEM on that day. The $y$-axis has a logarithmic scale to show more detail.

Figure 4 shows the profits for each of the power levels we tried for the peak day. The profit grows linearly with the power level of the NEM bid block for the case where turbines are used (empty circles) as well as the case where reciprocating engines are used (filled circles). The reason is that in this case, the income generated by the NEM bid dwarfs the income generated by satisfying local demand. Table 1 shows that for the peak price day, the income from satisfying local demand as well as the variable costs are almost insignificant compared to the income from the NEM bid.

To see how much power the control strategy would provide to the NEM over a whole year, we used the half hourly resolution price data of AEMO for the year 2012. Table 2 shows a summary of our results.

Since the profit distribution was very similar for the turbines and the reciprocating engines but the total profit for the engines was higher, we only present plots for the results of the experiments using the Cummins GGFE generators in this section. 


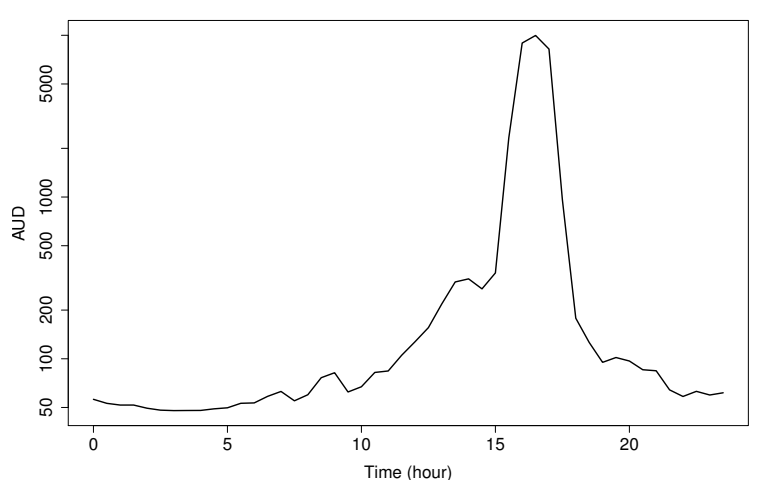

Figure 3. 29 November 2012 Power prices in the Victorian part of the NEM

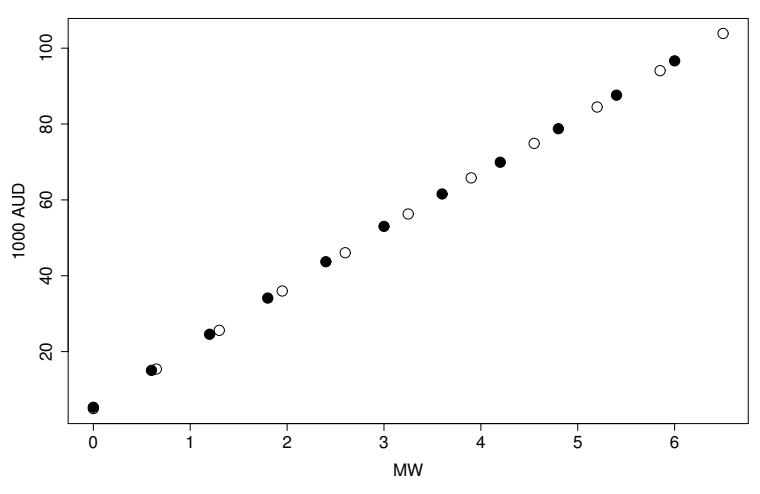

Figure 4. 29 November 2012

Profits against power level of NEM bid

\begin{tabular}{l|c|c|c|c}
\hline & \multicolumn{2}{c|}{ Average Day } & \multicolumn{2}{c}{ Peak Day } \\
\multicolumn{1}{c}{ Micro-Turbine } & Reciprocating & Micro-Turbine & Reciprocating \\
\hline Power level & $2.6 \mathrm{MW}$ & $2.4 \mathrm{MW}$ & $6.5 \mathrm{MW}$ & $6.0 \mathrm{MW}$ \\
Block length & $2 \mathrm{~h}$ & $2.5 \mathrm{~h}$ & $5.5 \mathrm{~h}$ & $5.5 \mathrm{~h}$ \\
NEM income & $\$ 141$ & $\$ 162$ & $\$ 104,086$ & $\$ 96,080$ \\
Local income & $\$ 8,220$ & $\$ 9,278$ & $\$ 7,685$ & $\$ 8,528$ \\
Variable costs & $\$ 6,807$ & $\$ 7501$ & $\$ 11,572 \mathrm{AUD}$ & $\$ 11,522 \mathrm{AUD}$ \\
\hline Conv. heating costs & \multicolumn{2}{|c|}{$\$ 1,994$} & \multicolumn{2}{c}{$\$ 3,553$} \\
\hline Profit & $\$ 3,548$ & $\$ 3,933$ & $\$ 103,752$ & $\$ 96,639$
\end{tabular}

Table 1. Characteristics of the best solutions found for the average day and peak day scenarios

Figure 5 shows the variable profit for each day in 2012 on a logarithmic scale. These profits are the variable revenues (revenue from NEM-bid and electricity provided to the apartment building plus the heating cost in the conventional case) minus the variable costs. The days with high NEM prices are clearly apparent given the very large profit achieved on these days. The average variable profit over the whole of 2012 was 3061.44 AUD per day.

We also collected data on the amount of $\mathrm{CO}_{2}$ emissions saved by using the CHP-system instead of heating with boilers and buying all electricity from the grid. According to the State Government of Victoria (2002), $1.444 \mathrm{~kg}$ of $\mathrm{CO}_{2}$ equivalent is emitted for every kilowatt of electricity produced currently in Victoria (mostly by brown coal fired power stations). For each gigajoule of natural gas used, the amount of $\mathrm{CO}_{2}$ equivalent produced is $51.7 \mathrm{~kg}$.

To calculate the $\mathrm{CO}_{2}$ savings, we compute the amount of $\mathrm{CO}_{2}$ emitted to generate the same amount of electricity that the CHP-generators produced during 2012 (NEM-bid and local use) and added the emissions produced

\begin{tabular}{l|c|c|c} 
& Micro-Turbine & Reciprocating Engine & Unit \\
\hline Mean daily profit & 2191.64 & 3061.44 & AUD \\
Total profit & $802,141.11$ & $1,120,487.18$ & AUD \\
Mean daily e-production & 90.94 & 96.98 & MWh \\
Total e-production & 33,283 & 35,494 & MWh \\
Capacity factor & 0.58 & 0.67 & \\
Mean daily $\mathrm{CO}_{2}$ saved & 75.75 & 83.10 & $\mathrm{t}$ \\
Total $\mathrm{CO}_{2}$ saved & 27,724 & 30,406 & $\mathrm{t}$
\end{tabular}

Table 2. Comparison of using micro-turbine or reciprocating engine in our apartment NEM CHP scenario 


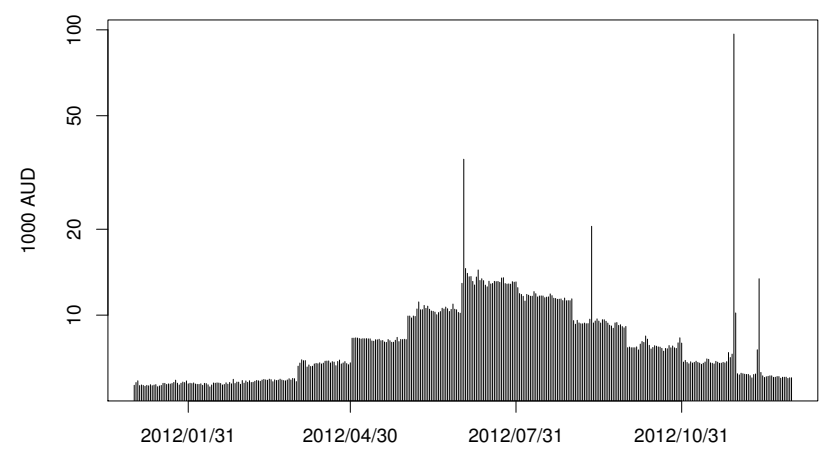

Figure 5. Daily variable profits for 2012 using our operating strategy. Note that the $y$-axis is logarithmic and that negative profits have been left out

using a conventional heating system (boilers) to provide all heat load for that year. From this value, we subtracted all $\mathrm{CO}_{2}$ emissions created by the reciprocating engines and boilers in our CHP-solution. The results are shown in Figure 6.

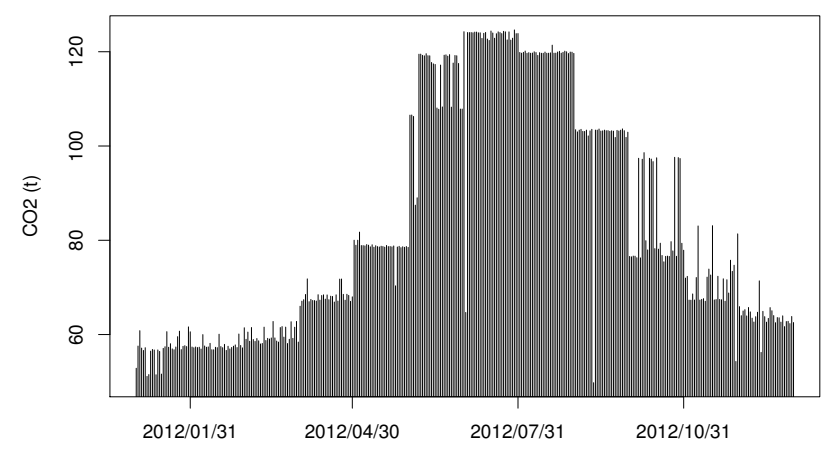

Figure 6. Tonnes of $\mathrm{CO}_{2}$ saved for each day in 2012 using the CHP-system with reciprocating engines

The savings are around $60 \mathrm{t}$ a day in summer and go up to $120 \mathrm{t}$ in winter. The mean daily savings are $83.10 \mathrm{t}$ and the total savings for 2012 are 30,406 t. This represents a $52 \%$ reduction in annual emissions compared to satisfying the heat and electrical demand of the apartment network by conventional means.

\section{Conclusion}

We have presented a linear programming based optimisation strategy for controlling micro-CHP generators that provide heating, hot water and electricity for apartment blocks.

By running the optimisation for each day of the year 2012, we show that an operator running CHP-generators according to the business model we describe in this paper must make sure that he or she can profit from the days with extreme NEM prices. A business model where the operator can only sell electricity to the occupants of the apartment blocks for the retail price has a much smaller earning potential. Therefore, allowing distributed generation operators with significant capacity to participate in the NEM should greatly encourage the installation of these devices.

Our results also show that the savings in $\mathrm{CO}_{2}$ emissions from using CHP-generators in apartment buildings can be substantial. 


\section{REFERENCES}

AEMO Ltd (2010, July). An introduction to Australia's National Electricty Market. www . aemo.com . au/ corporate/0000-0262.pdf.

Aki, H., S. Yamamoto, J. Kondoh, T. Maeda, H. Yamaguchi, A. .Murata, and I. .Ishii: (2005). A network of residential fuel cells and operational strategies: Evaluation with a pc simulator and an experimental system. In Power Engineering Society General Meeting, Volume 3, pp. 2109-2114. IEEE.

Alanne, K. and A. Saari (2004). Sustainable small-scale CHP technologies for buildings: the basis for multiperspective decision-making. Renewable and Sustainable Energy Reviews 8, 401-431.

Arcuri, P., G. Florio, and P. Fragiacomo (2007, August). A mixed integer programming model for optimal design of trigeneration in a hospital complex. Energy 32(8), 1430-1447.

Bazmi, A. A. and G. Zahedi (2011, October). Sustainable energy systems: Role of optimization modeling techniques in power generation and supply-A review. Renewable and Sustainable Energy Reviews 15(8), 3480-3500.

Cardona, E., P. Sanninob, A. Piacentinoa, and F. Cardona (2006). Energy saving in airports by trigeneration. part ii: Short and long term planning for the malpensa 2000 CCHP plant. Applied Thermal Engineering 26, 1437-1447.

Carvalho, M., M. A. Lozano, and L. M. Serra (2012, March). Multicriteria synthesis of trigeneration systems considering economic and environmental aspects. Applied Energy 91(1), 245-254.

Casisi, M., P. Pinamonti, and M. Reini (2009, December). Optimal lay-out and operation of combined heat \& power (CHP) distributed generation systems. Energy 34(12), 2175-2183.

Cho, H., P. J. Mago, R. Luck, and L. M. Chamra (2009, December). Evaluation of CCHP systems performance based on operational cost, primary energy consumption, and carbon dioxide emission by utilizing an optimal operation scheme. Applied Energy 86(12), 2540-2549.

Combined Heat and Power Partnership, US Environmental Protection Agency (2002). Catalog of CHP technologies. http://www.epa.gov/chp/pdf/catalog_entire.pdf.

Fazlollahi, S., P. Mandel, G. Becker, and F. Maréchal (2012, September). Methods for multi-objective investment and operating optimization of complex energy systems. Energy 45(1), 12-22.

Hernandez-Aramburo, C. A., T. C. Green, and N. Mugniot (2005). Fuel consumption minimization of a microgrid. IEEE Transactions on Industry Applications 41(3), 673-681.

Kavvadias, K. and Z. Maroulis (2010, February). Multi-objective optimization of a trigeneration plant. Energy Policy 38(2), 945-954.

Kong, X. Q., R. Z. Wang, and X. H. Huang (2005). Energy optimization model for a CCHP system with available gas turbines. Applied Thermal Engineering 25, 377-391.

Rooijers, F. J. and R. A. M. van Amerongen (1994). Static economic dispatch for co-generation systems. IEEE Transactions on Power Systems 9(3), 1392-1398.

Song, Y. H., C. S. Chou, and T. J. Stonham (1999). Combined heat and power economic dispatch by improved ant colony search algorithm. Electric Power Systems Research 52(2), 115-121.

State Government of Victoria (2002, June). Calculating energy use and greenhouse emissions.

Weber, C., F. Maréchal, D. Favrat, and S. Kraines (2006, September). Optimization of an SOFC-based decentralized polygeneration system for providing energy services in an office-building in tōkyō. Applied Thermal Engineering 26(13), 1409-1419.

Weiskircher, R., S. Dunstall, and N. Kontoleon (2008). Controlling chp micro-turbines as a virtual power plant. In Sustainable Buildings 2008, Melbourne, September 21-25. [\#2694]. 